\title{
Preparação de compósitos alumina-mulita de baixo custo via sinterização reativa entre uma argila caulinítica da Paraíba e hidróxido de alumínio
}

\section{(Preparation of low-cost alumina-mullite composites via reactive sintering between a kaolinite clay from Paraíba and aluminum hydroxide)}

\author{
S. G. Medeiros', R. P. S. Dutra ${ }^{2}$, J. P. F. Grilo , A. E. Martinelli, C. A. Paskocimas', D. A. Macedo,"* \\ ${ }^{1}$ Programa de Pós-Graduação em Ciência e Engenharia de Materiais, UFRN, Natal, Brasil 59078-970 \\ ${ }^{2}$ Programa de Pós-Graduação em Ciência e Engenharia de Materiais, UFPB, João Pessoa, Brasil 58051-900 \\ ${ }^{3}$ Departamento de Materiais \& Engenharia Cerâmica, University of Aveiro, Aveiro, Portugal 3810-193 \\ sloany@outlook.com, ricardopsd@gmail.com,grilo.jpf@gmail.com, martinelli.ufrn@gmail.com, \\ paskocimas@uol.com.br,*damaced@gmail.com
}

\begin{abstract}
Resumo
Este estudo aborda os efeitos do processamento na microestrutura e nas propriedades de compósitos alumina-mulita via sinterização reativa de uma mistura argila caulinítica e hidróxido de alumínio. Amostras prensadas a $40 \mathrm{MPa}$ foram sinterizadas entre 1300 e $1600{ }^{\circ} \mathrm{C}$. As propriedades tecnológicas foram determinadas em função da temperatura de sinterização. A avaliação das fases cristalinas e da microestrutura foi realizada por difração de raios X e microscopia eletrônica. Os resultados indicaram a obtenção de mulita e alumina a partir de $1300{ }^{\circ} \mathrm{C}$. Para sinterizações acima de $1450{ }^{\circ} \mathrm{C}$ foram obtidos valores de porosidade aparente inferiores a $0,8 \%$ e tensão de ruptura à flexão superior a $40 \mathrm{MPa}$. Amostras com morfologia bimodal (grãos equiaxiais e alongados) e resistência mecânica de $70 \mathrm{MPa}$ foram obtidas após sinterização a $1600{ }^{\circ} \mathrm{C}$. Este estudo demonstra a possibilidade de preparar compósitos alumina-mulita de baixo custo e com propriedades tecnológicas compatíveis com as de cerâmicas produzidas por companhias com grande atuação no mercado internacional de produtos refratários.
\end{abstract}

Palavras-chave: caulinita, mulita, alumina, microestrutura, propriedades tecnológicas.

\begin{abstract}
This work aimed to evaluate the effects of processing on microstructure and properties of alumina-mullite composites via reactive sintering of a mixture of kaolinite clay and aluminum hydroxide. Cylindrical pellets were pressed at $40 \mathrm{MPa}$ and sintered between 1300 and $1600{ }^{\circ} \mathrm{C}$. The technological properties were determined as a function of sintering temperature. The evaluation of crystalline phases and microstructure was performed by X-ray diffraction and electron microscopy. Structural results indicate the attainment of mullite and alumina at $1300^{\circ} \mathrm{C}$. Apparent porosity below $0.8 \%$ and flexural strength higher than $40 \mathrm{MPa}$ were obtained for sintering temperatures above $1450^{\circ} \mathrm{C}$. A flexural strength as high as $70 \mathrm{MPa}$ was obtained after sintering at $1600{ }^{\circ} \mathrm{C}$. This study demonstrates the possibility of preparing low cost alumina-mullite composites with technological properties compatible with those of ceramics produced by companies with large operations in the international market of refractory products.

Keywords: kaolinite, mullite, alumina, microstructure, technological properties.
\end{abstract}

\section{INTRODUÇÃO}

Mulita $\left(3 \mathrm{Al}_{2} \mathrm{O}_{3} \cdot 2 \mathrm{SiO}_{2}\right)$ é um alumino-silicato de grande importância tecnológica comumente obtido por reação no estado sólido (sinterização reativa) entre caulinita $\left[\mathrm{Al}_{2} \mathrm{Si}_{2} \mathrm{O}_{5}(\mathrm{OH})_{4}\right]$ e alumina $\left(\mathrm{Al}_{2} \mathrm{O}_{3}\right)$ em temperaturas a partir de $1300{ }^{\circ} \mathrm{C}$ [1-3]. A proporção mássica estequiométrica da mulita corresponde a $71,8 \%$ de $\mathrm{Al}_{2} \mathrm{O}_{3}$ e $28,2 \%$ de $\mathrm{SiO}_{2}$, podendo ser obtida em formulações contendo até aproximadamente $74 \%$ de $\mathrm{Al}_{2} \mathrm{O}_{3}$. Devido ao seu conjunto de propriedades especiais, tais como, alto ponto de fusão (1830 ${ }^{\circ} \mathrm{C}$ ), elevado módulo de ruptura, boa resistência ao choque térmico, à erosão e ao ataque químico, e baixo coeficiente de expansão térmica $\left(\sim 4,5 \times 10^{-6} \mathrm{~K}^{-1}\right)$, a mulita tem se qualificado como uma das mais importantes cerâmicas refratárias da atualidade.

A obtenção de mulita por sinterização reativa de fontes sílico-aluminosas ocorre por difusão iônica das espécies envolvidas; íons de $\mathrm{Al}^{3+}$ difundem-se para o interior das camadas de $\mathrm{SiO}_{2}$ formadas durante a decomposição da caulinita $\left(>500{ }^{\circ} \mathrm{C}\right.$ ), caracterizando a mulitização como um processo lento e termicamente ativado [4-7]. A adição de alumina a uma matriz de mulita tem um efeito positivo nas propriedades mecânicas do compósito, sendo um método atrativo para preparar compósitos cerâmicos de baixa densidade para aplicações estruturais, elétricas 
(componentes isolantes) e refratárias [8]. Matérias-primas naturais e sintéticas, como argilas, alumina, caulinita e isopropóxido de alumínio, têm sido utilizadas para produzir compósitos alumina-mulita $[2,8,9]$.

Neste trabalho, compósitos alumina-mulita de baixo custo foram preparados via sinterização reativa de uma mistura contendo uma argila caulinítica do estado da Paraíba (Brasil) e hidróxido de alumínio (fonte adicional de $\mathrm{Al}$ ) comercial. O uso de uma matéria-prima natural rica em $\mathrm{Si}$ e Al, com boa disponibilidade na Paraíba, torna a rota de preparação usada neste trabalho adequada para a produção em larga escala de compósitos cerâmicos alumina-mulita. Os efeitos da temperatura de sinterização na formação de mulita, na microestrutura e nas propriedades tecnológicas dos compósitos foram discutidos.

\section{MATERIAIS E MÉTODOS}

Cerâmicas de alumina-mulita foram preparadas por sinterização reativa de uma argila caulinítica e hidróxido de alumínio. O material argiloso (fonte natural de $\mathrm{Si}$ e $\mathrm{Al}$ ), proveniente do estado da Paraíba (Brasil), apresenta baixo custo e boa disponibilidade local. O hidróxido de alumínio (usado como fonte adicional de alumina) foi adquirido da Synth (Brasil). A argila como recebida foi peneirada em granulometria inferior a $0,074 \mathrm{~mm}$ (peneira $\mathrm{n}^{\circ} 200 \mathrm{da}$ ABNT), seca em estufa a $110^{\circ} \mathrm{C}$ por $24 \mathrm{~h}$ e caracterizada por difração de raios X (DRX, Shimadzu XRD-7000), fluorescência de raios X (FRX, Shimadzu EDX-700) e análise termogravimétrica (TG) simultânea com análise térmica diferencial (DTA, Shimadzu DTG-60H). As medidas de DRX foram realizadas usando varredura angular $2 \theta$ entre $10^{\circ}$ e $70^{\circ}$, passo de $0,02^{\circ}$ e tempo de contagem de 2 s/passo usando radiação $\mathrm{K} \alpha$ do cobre $(\lambda=1,5418 \AA)$ obtida com $40 \mathrm{kV}$ e corrente de filamento de $40 \mathrm{~mA}$. A perda ao fogo foi determinada com base no resultado de TG. Com os resultados de FRX e DRX realizou-se a análise racional da argila. O pó de hidróxido de alumínio foi caracterizado apenas por análise térmica (TG-DTA).

Uma formulação cerâmica foi preparada misturando $33 \%$ em massa de argila com $67 \%$ em massa de hidróxido de alumínio, correspondendo a um excesso de alumina em relação à composição ideal da mulita estequiométrica $\left(3 \mathrm{Al}_{2} \mathrm{O}_{3} \cdot 2 \mathrm{SiO}_{2}\right)$. Essa formulação foi moída por $3 \mathrm{~h} \mathrm{em}$ moinho de bolas (via úmida: água destilada) usando uma relação mássica material/bolas de 1:2. Os pós secos foram peneirados em peneira $\mathrm{n}^{\circ} 35$ da ABNT. Corpos cerâmicos retangulares $(61 \mathrm{~mm}$ x $21 \mathrm{~mm}$ x 7,6 mm) foram preparados por prensagem uniaxial a $40 \mathrm{MPa}$ e posteriormente sinterizados entre 1300 e $1600{ }^{\circ} \mathrm{C}$ por $3 \mathrm{~h}$ em atmosfera de ar. A identificação das fases cristalinas e a caracterização microestrutural de amostras sinterizadas foram realizadas por difratometria de raios $\mathrm{X}$ e microscopia eletrônica de varredura (MEV, LEO 1430). As propriedades físicomecânicas foram avaliadas por ensaios de retração linear de queima, absorção de água, porosidade aparente, massa específica aparente e ruptura à flexão em três pontos em máquina de ensaios universal (Shimadzu AG-X $10 \mathrm{kN}$ ) usando uma velocidade de $0,5 \mathrm{~mm} / \mathrm{min}$.

\section{RESULTADOS E DISCUSSÃO}

\section{Caracterização das matérias-primas}

O comportamento térmico das matérias-primas (argila e hidróxido de alumínio) é mostrado na Fig. 1. Como pode ser observado da curva de análise termodiferencial (DTA) da Fig. 1a, a argila apresenta um primeiro pico endotérmico entre a temperatura ambiente e aproximadamente $100{ }^{\circ} \mathrm{C}$ que pode ser atribuído à eliminação de água adsorvida na sua superfície. Um segundo pico endotérmico próximo a $500{ }^{\circ} \mathrm{C}$ está associado ao processo de desidroxilação, característico da transformação da caulinita em metacaulinita. $\mathrm{O}$ pico exotérmico entre 990 e $1000{ }^{\circ} \mathrm{C}$ é característico do argilomineral caulinita, sendo classicamente atribuído à formação do espinélio Si-Al e sílica amorfa e/ou nucleação da mulita primária (mulita 2:1). A formação da mulita primária ocorre a partir da interação da sílica amorfa com
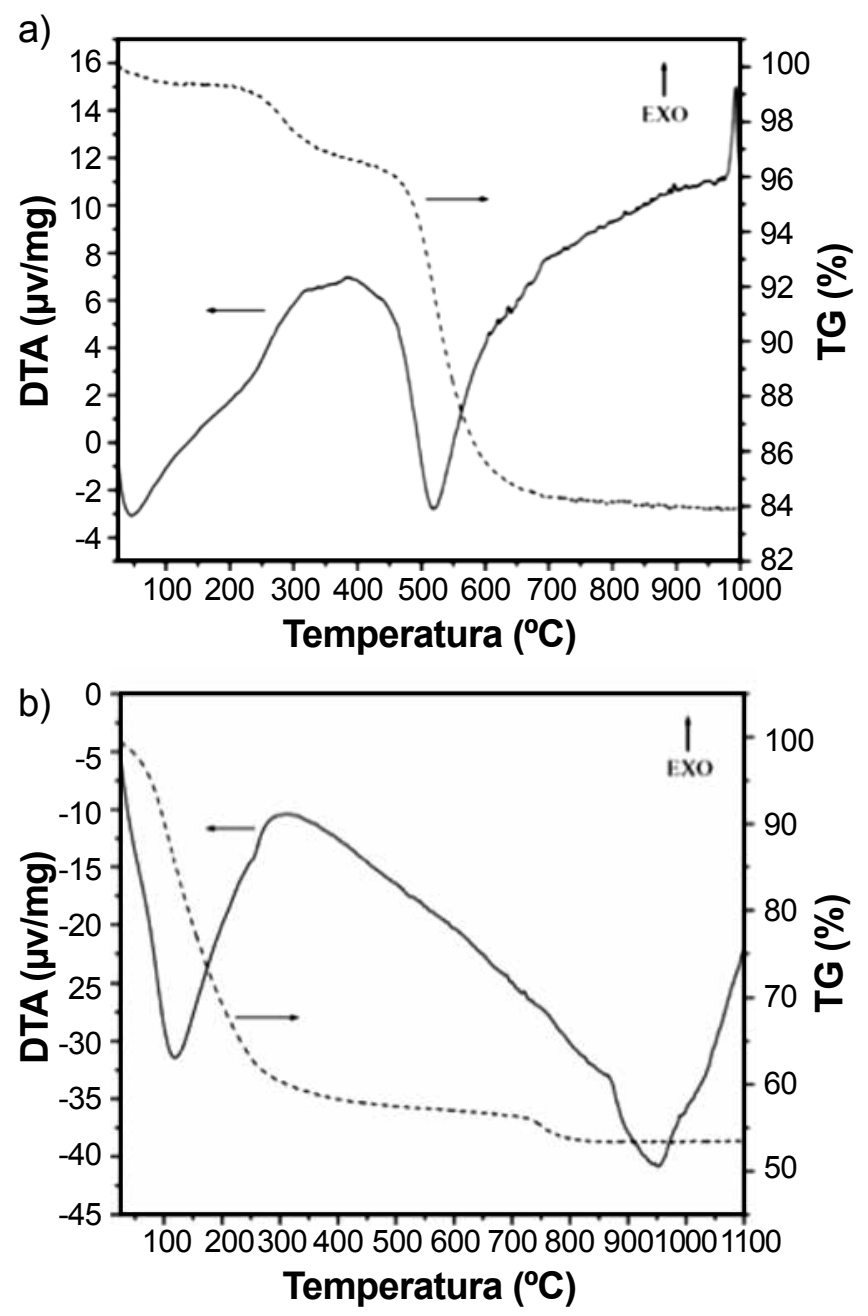

Figura 1: Curvas de TG/DTA de: (a) argila e (b) hidróxido de alumínio.

[Figure 1: TG/DTA curves of: (a) clay, and (b) aluminum hydroxide.] 
alumina da caulinita ou da fase espinélio proveniente da metacaulinita [10-12]. A curva termogravimétrica mostra uma contínua perda de massa da temperatura ambiente até cerca de $600{ }^{\circ} \mathrm{C}$. A perda de massa entre 30 e $400{ }^{\circ} \mathrm{C}$ está associada a processos de desidratação (eliminação da água adsorvida e interlamelar) e oxidação de matéria orgânica. A acentuada perda de massa entre 400 e $600{ }^{\circ} \mathrm{C}(>10 \%)$ é devida ao processo de desidroxilação da caulinita, em conformidade com o pico exotérmico observado na curva de DTA. A perda de massa ao fogo calculada a partir da curva termogravimétrica (entre 30 e $1000{ }^{\circ} \mathrm{C}$ ) foi de $16 \%$. A partir de $1300{ }^{\circ} \mathrm{C}$ (fora do limite de detecção do equipamento) ocorre a formação de mulita secundária (mulita 3:2) como resultado da interação da alumina de transição derivada do hidróxido de alumínio com a sílica remanescente da transformação da caulinita [13].

$\mathrm{Na}$ caracterização térmica do hidróxido de alumínio (Fig. 1b), um evento endotérmico a aproximadamente $100{ }^{\circ} \mathrm{C}$ é referente à desidratação do hidróxido. A curva termogravimétrica indica o fim do processo de decomposição térmica a aproximadamente $800^{\circ} \mathrm{C}$. A principal contribuição para a acentuada perda de massa até $800{ }^{\circ} \mathrm{C}$ é a conversão do $\mathrm{Al}(\mathrm{OH})_{3}$ em uma série de fases de alumina de transição, tais como $\gamma, \delta$ e $\theta$. De acordo com a curva de DTA, o pico de transformação de $\theta-\mathrm{Al}_{2} \mathrm{O}_{3}$ a $\alpha-\mathrm{Al}_{2} \mathrm{O}_{3}$ começa a se formar acima de $1000{ }^{\circ} \mathrm{C}$. A literatura relata que esta transformação de fase ocorre próximo a $1250^{\circ} \mathrm{C}[14,15]$. Devido à estreita faixa de medida do analisador térmico empregado (30 a $1100{ }^{\circ} \mathrm{C}$ ), não foi possível observar o pico característico desta transformação de fase.

A caracterização mineralógica da argila é mostrada na Fig. 2. De acordo com o difratograma de raios $X$, a argila é predominantemente composta pelo argilomineral caulinita, em bom acordo com os resultados de análise térmica, associado às fases acessórias mica e quartzo. A composição química da argila (expressa na forma de percentual dos óxidos constituintes) é apresentada na Tabela I. O elevado

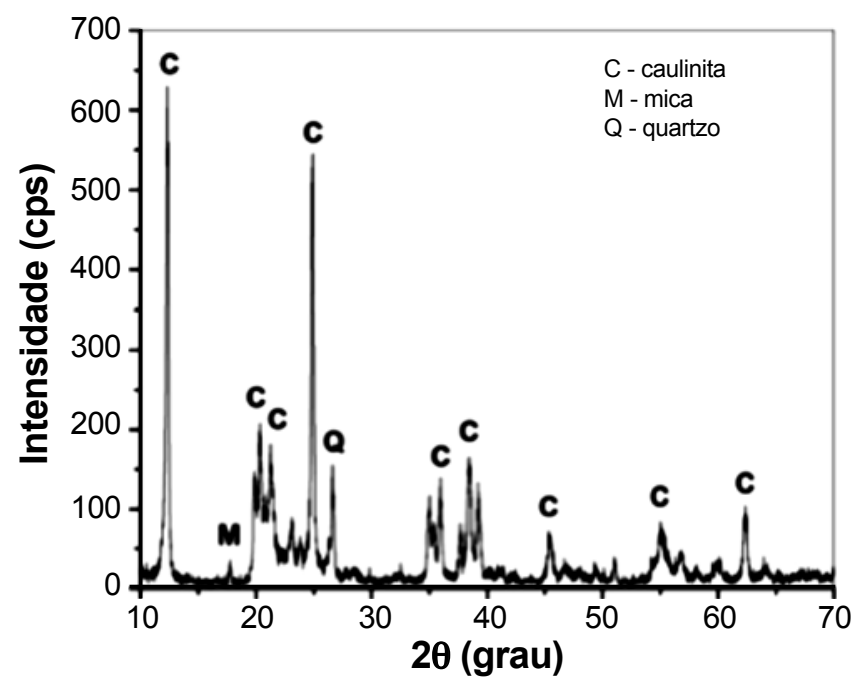

Figura 2: Difratograma de raios $\mathrm{X}$ da argila. [Figure 2: X-ray diffraction pattern of the clay.]
Tabela I - Composição química da argila obtida por FRX. [Table I - Chemical composition of the clay obtained by XFR.]

\begin{tabular}{cc}
\hline Constituinte & Percentual mássico \\
\hline $\mathrm{SiO}_{2}(\%)$ & 57,6 \\
$\mathrm{Al}_{2} \mathrm{O}_{3}(\%)$ & 41,0 \\
$\mathrm{~K}_{2} \mathrm{O}(\%)$ & 0,7 \\
$\mathrm{Fe}_{2} \mathrm{O}_{3}(\%)$ & 0,5 \\
$\mathrm{MgO}(\%)$ & 0,08 \\
Outros $(\%)$ & 0,12 \\
\hline
\end{tabular}

teor de óxido de silício $(57,6 \%)$ é devido à presença de caulinita $\left[\mathrm{Al}_{2} \mathrm{Si}_{2} \mathrm{O}_{5}(\mathrm{OH})_{4}\right]$, quartzo $\left(\mathrm{SiO}_{2}\right)$ e mica muscovita $\left[\mathrm{KAl}_{2} \mathrm{Si}_{3} \mathrm{AlO}_{10}(\mathrm{OH})_{2}\right]$. O óxido de alumínio $\left(\mathrm{Al}_{2} \mathrm{O}_{3}\right)$ também está associado à presença do mineral caulinita. $\mathrm{O}$ baixo teor de $\mathrm{Fe}_{2} \mathrm{O}_{3}(<3 \%)$ caracteriza a matéria-prima como sendo de cor clara após queima. De acordo com a metodologia de análise racional proposta por [16], a argila contém $86,7 \%$ de caulinita, $9 \%$ de quartzo e $4,3 \%$ de mica. Com base nestes resultados, a argila caulinítica utilizada neste trabalho tem grande potencial para ser utilizada como matéria-prima para a obtenção de cerâmicas refratárias à base de mulita.

\section{Caracterização dos corpos de prova}

O difratograma de raios X da Fig. 3 mostra que a mistura argila + hidróxido de alumínio é completamente convertida em mulita (JCPDS 15-0776) e $\alpha$-alumina (JCPDS 75-1862) após sinterização a $1300{ }^{\circ} \mathrm{C}$ por $1 \mathrm{~h}$. Não há evidência de formação de cristobalita $\left(2 \theta=20,8^{\circ}\right)$, indicando que a alumina reativa (derivada da desidroxilação do hidróxido) reage com a sílica remanescente da transformação da caulinita para cristalizar mulita a temperaturas tão baixas quanto $1300^{\circ} \mathrm{C}$. Isto pode ser atribuído à boa homogeneidade de fase e à alta reatividade química proporcionadas pelas fases de alumina metaestáveis derivadas da calcinação do hidróxido de alumínio. Uma pequena convexidade na região de $2 \theta$ de 20 a $30^{\circ}$ sugere a presença de sílica amorfa. Sainz et al. [17] também relataram a obtenção de cristais de mulita primária (com aproximadamente 300 a $500 \AA$ de tamanho) após queima de uma mistura de caulinita/ $\alpha$-alumina a 1300 ${ }^{\circ} \mathrm{C}$ por $4 \mathrm{~h}$. De acordo com estes autores, a esta temperatura a reação entre caulinita e $\alpha$-alumina foi limitada, havendo formação apenas de mulita primária. Por outro lado, quando a temperatura de sinterização foi aumentada para $1400{ }^{\circ} \mathrm{C}$ observaram a nucleação de pequenos cristais de mulita secundária ( $\sim 500 \AA$ ). A nucleação e o crescimento da mulita ocorrem na interface entre as partículas de $\mathrm{Al}_{2} \mathrm{O}_{3}$ e $\mathrm{SiO}_{2}$ por difusão de $\mathrm{Al}^{3+}$ e $\mathrm{Si}^{4+}$ através da rede cristalina. A alumina residual forma diferentes fases cristalinas de alumina (até atingir $\alpha$-alumina) dependendo da temperatura de sinterização [9].

Os difratogramas das amostras sinterizadas entre $1400 \mathrm{e}$ $1600{ }^{\circ} \mathrm{C}$ são apresentados na Fig. 4. A característica amorfa em $2 \theta$ de 20 a $30^{\circ}$ diminui com o aumento da temperatura 


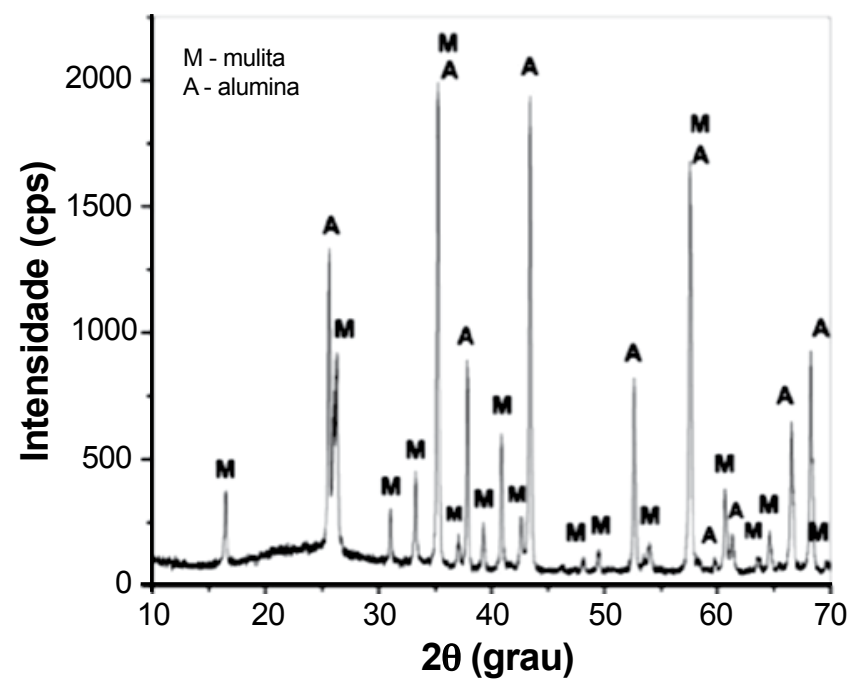

Figura 3: Difratograma de raios $\mathrm{X}$ da amostra sinterizada a $1300{ }^{\circ} \mathrm{C}$.

[Figure 3: X-ray diffraction pattern of the sample sintered at $\left.1300^{\circ} \mathrm{C}.\right]$

de sinterização, indicando que a formação de mulita reduz a quantidade de fase vítrea rica em $\mathrm{SiO}_{2}$. Como pode ser observado, não foram detectadas outras fases além de mulita e alumina identificadas na amostra sinterizada a $1300{ }^{\circ} \mathrm{C}$. Os planos de difração (110), (120), (210), (001), (220), (111), (201), (121), (230), (041), (331), (002), (250) e (520) característicos da fase mulita (JCPDS 15-0776) estão presentes a partir de $1400{ }^{\circ} \mathrm{C}$. Em comparação ao difratograma obtido para a amostra sinterizada a $1300{ }^{\circ} \mathrm{C}$, que apresenta apenas uma reflexão de mulita em $2 \theta$ de $26^{\circ}$, as amostras sinterizadas a partir de $1400{ }^{\circ} \mathrm{C}$ exibem duas reflexões, planos (120) e (210), o que é classicamente atribuído à transformação de mulita tetragonal para ortorrômbica (mulita secundária) [18]. Portanto, a mistura argila caulinítica/hidróxido de alumínio usada neste trabalho

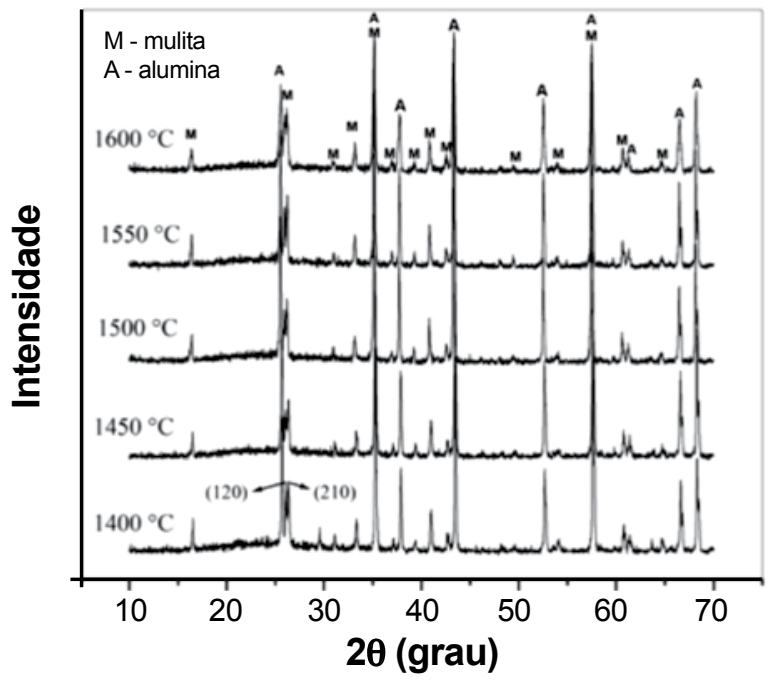

Figura 4: Difratogramas de raios $\mathrm{X}$ de amostras sinterizadas entre 1400 e $1600^{\circ} \mathrm{C}$.

[Figure 4: X-ray diffraction patterns of samples sintered between 1400 and $1600^{\circ} \mathrm{C}$.] permitiu obter mulita secundária à mesma temperatura relatada em [17].

As microestruturas dos compósitos alumina-mulita sinterizados a 1400 e $1600{ }^{\circ} \mathrm{C}$ são apresentadas na Fig. 5. A amostra sinterizada a $1600{ }^{\circ} \mathrm{C}$ (Fig. 5b) apresenta uma
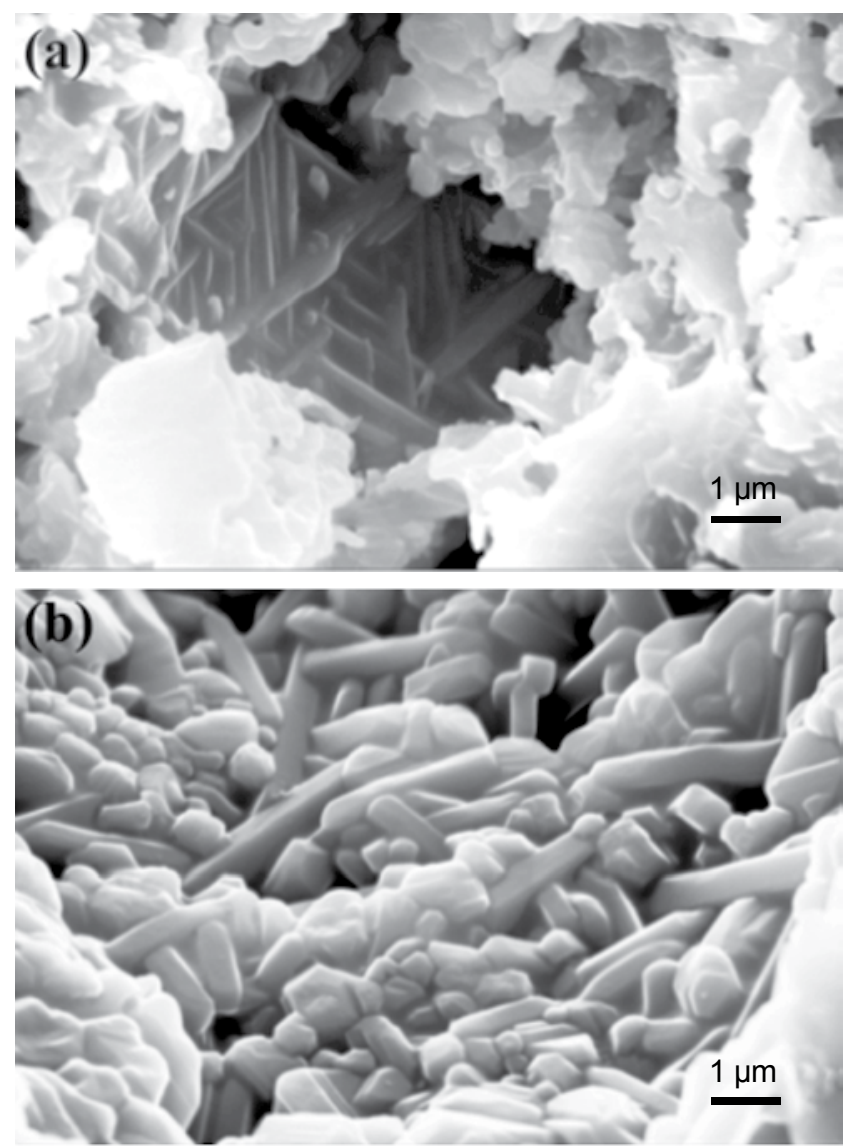

Figura 5: Microestruturas das amostras sinterizadas a (a) $1400{ }^{\circ} \mathrm{C}$ e (b) $1600{ }^{\circ} \mathrm{C}$.

[Figure 5: Microstructures of samples sintered at (a) $1400^{\circ} \mathrm{C}$, and (b) $\left.1600^{\circ} \mathrm{C}.\right]$

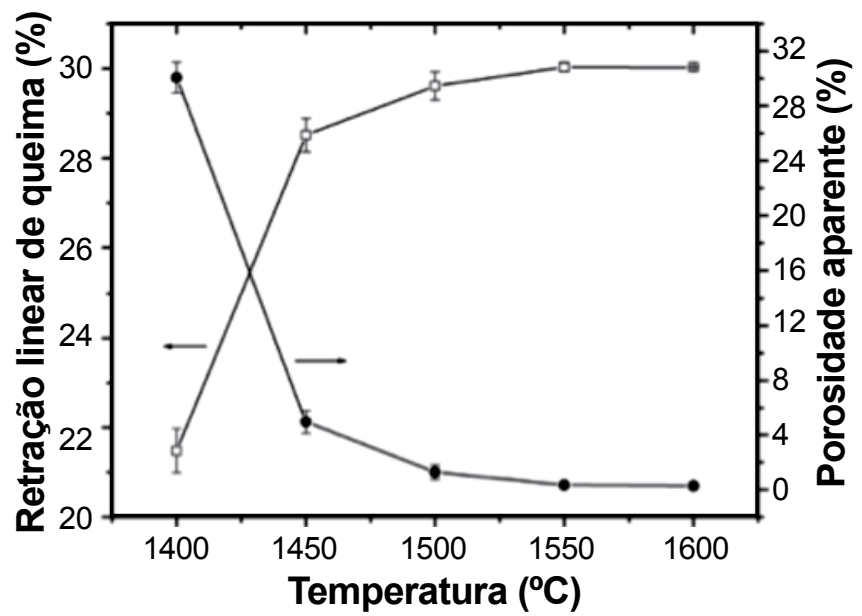

Figura 6: Retração linear e porosidade aparente em função da temperatura de sinterização.

[Figure 6: Linear shrinkage and apparent porosity as a function of sintering temperature.] 
morfologia bimodal, composta por grãos equiaxiais de mulita secundária (e alumina) e grãos alongados de mulita primária. Estas micrografias evidenciam que ainda há presença de mulita primária (nucleada na caulinita) após sinterização a $1400^{\circ} \mathrm{C}$ (Fig. 5a) e que o crescimento de grão (alongado) e teor relativo desta fase diminui com a elevação da temperatura de sinterização, como esperado.

A Fig. 6 apresenta os resultados da retração linear e porosidade aparente em função da temperatura de sinterização. Observa-se que a retração linear aumenta com a temperatura de sinterização até a temperatura de $1550{ }^{\circ} \mathrm{C}$.
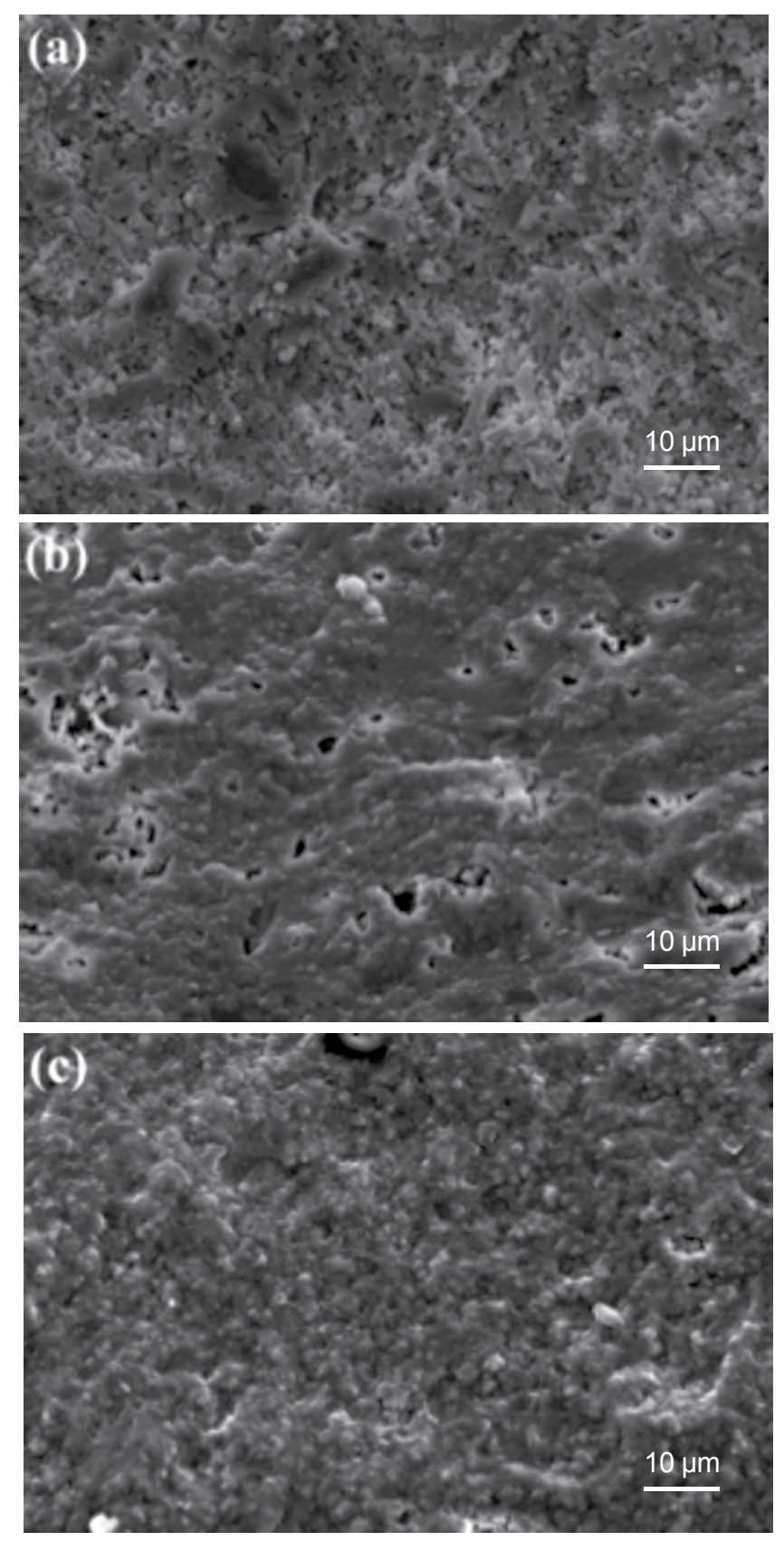

Figura 7: Micrografias obtidas por microscopia eletrônica de varredura de superfícies de fratura de amostras sinterizadas a (a) $1400{ }^{\circ} \mathrm{C}$, (b) $1500{ }^{\circ} \mathrm{C}$ e (c) $1600{ }^{\circ} \mathrm{C}$.

[Figure 7: SEM micrographs of fracture surfaces of samples sintered at (a) $1400^{\circ} \mathrm{C}$, (b) $1500^{\circ} \mathrm{C}$, and (c) $1600^{\circ} \mathrm{C}$.]

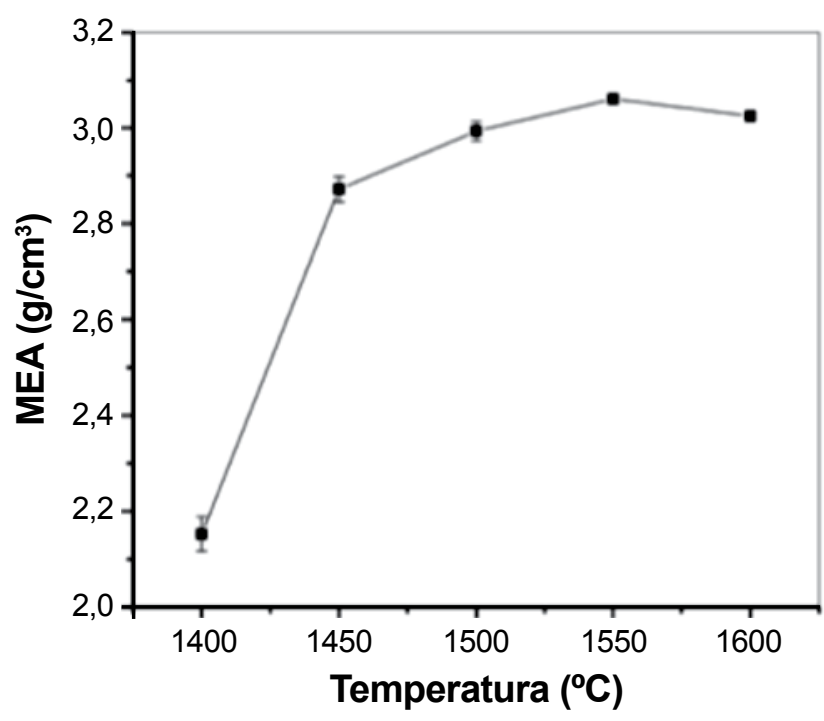

Figura 8: Massa específica aparente em função da temperatura de sinterização.

[Figure 8: Bulk density as a function of sintering temperature.]

Este comportamento de sinterização é principalmente devido ao reduzido tamanho de partícula da caulinita e das fases de alumina de transição. Em altas temperaturas (acima de $1400^{\circ} \mathrm{C}$ ) o mecanismo de fase líquida (rica em sílica) também contribui para o processo de sinterização e a retração linear atinge $30 \%$ a $1550-1600{ }^{\circ} \mathrm{C}$. A notável desaceleração na taxa de retração linear em temperaturas mais altas (acima de $1450{ }^{\circ} \mathrm{C}$ ) pode ser atribuída ao efeito de barreira causado pelo aumento do teor de mulita, estagnando o processo de retração [19]. A progressiva redução da porosidade aparente, sobretudo acima de $1450{ }^{\circ} \mathrm{C}$ é um indicativo da alta densificação atingida pela mistura argila/ hidróxido, em bom acordo com as imagens de microscopia eletrônica da Fig. 7.

O início da reação entre sílica amorfa e alumina, formando mulita secundária, marca o começo da conversão de $\mathrm{Al}$ octaédrico (na alumina) para $\mathrm{Al}$ tetraédrico. Isto resulta em uma expansão gradual que balanceia a retração volumétrica devido à sinterização [7]. Como resultado, ocorre uma recuperação gradual do volume e uma pequena diminuição de densidade (expressa como massa específica aparente, MEA) é observada após sinterização a $1600{ }^{\circ} \mathrm{C}$ (Fig. 8). A resistência mecânica dos compósitos obtidos neste trabalho aumentou com a temperatura de sinterização, como esperado. Valores de resistência em torno de 20, 45 e $70 \mathrm{MPa}$ foram obtidos para amostras sinterizadas a 1400,1500 e $1600{ }^{\circ} \mathrm{C}$, respectivamente. O conjunto de propriedades obtidas para as amostras sinterizadas a $1600^{\circ} \mathrm{C}$ (70 MPa, absorção de água de $0,09 \%$ e porosidade aparente de $0,27 \%$ ) é compatível como o de cerâmicas comerciais de mulita (Mulcoa 70) produzidas pela C-E Minerals, companhia chinesa especializada em minerais industriais e com grande atuação no mercado de produtos refratários. $\mathrm{O}$ teor de alumina presente na mulita foi calculado usando a relação proposta por Ban e Okada [20]. De acordo com estes autores, o percentual molar de alumina $\left(\% \mathrm{~mol} \mathrm{Al}_{2} \mathrm{O}_{3}\right)$ 
da fase mulita pode ser obtido (com uma incerteza de apenas $1,5 \%$ ) a partir das intensidades dos picos (220) e (111) da mulita, usando a seguinte expressão: $\% \mathrm{~mol} \mathrm{Al}_{2} \mathrm{O}_{3}=41,77 \mathrm{x}$ $\left(\mathrm{I}_{220} / \mathrm{I}_{111}\right)+27,6$. No presente trabalho, o valor de $\%$ mol $\mathrm{Al}_{2} \mathrm{O}_{3}$ para a amostra sinterizada a $1550{ }^{\circ} \mathrm{C}$ foi de $56 \%$. Sabendo-se que $\%$ mol $\mathrm{Al}_{2} \mathrm{O}_{3}$ na mulita secundária (mulita 3:2) é $\sim 60 \%$, a relação linear proposta por Ban e Okada é um método indireto que permite ratificar a obtenção de mulita secundária nos compósitos alumina-mulita preparados neste trabalho.

\section{CONCLUSÕES}

Com base nos resultados deste estudo, as seguintes conclusões podem ser apontadas: (1) cerâmicas de aluminamulita podem ser obtidas por sinterização de uma mistura contendo uma argila caulinítica da Paraíba e hidróxido de alumínio comercial; (2) a utilização de um pó fino e de alta reatividade de hidróxido de alumínio favoreceu o surgimento da fase $\alpha$-alumina e, como resultado, a retração linear de queima dos corpos de prova foi intensa, favorecendo também a densificação; (3) para sinterizações acima de 1450 ${ }^{\circ} \mathrm{C}$ foram obtidos corpos de prova cerâmicos com absorção de água inferior a $2 \%$ e tensão de ruptura à flexão superior a $40 \mathrm{MPa}$, propriedades que qualificam as cerâmicas obtidas neste trabalho para aplicações refratárias; (4) este estudo demonstra a possibilidade de controlar a microestrutura e as propriedades tecnológicas de compósitos cerâmicos alumina-mulita de baixo custo via tratamento térmico de uma formulação cerâmica contendo uma argila caulinítica abundante no estado da Paraíba.

\section{AGRADECIMENTOS}

Os autores agradecem ao Laboratório de Solidificação Rápida (LSR) da UFPB pela utilização do microscópio eletrônico de varredura.

\section{REFERÊNCIAS}

[1] K.G. Liu, G. Thomas, A. Caballero, J.S. Moya, S. Aza,
Acta Metall. Mater. 42 (1994) 489-495.

[2] C.Y. Chen, G.S. Lan, W.H. Tuan, J. Eur. Ceram. Soc. 20 (2000) 2519-2525.

[3] A.E. Souza, S.R. Teixeira, G.T.A. Santos, E. Longo, Cerâmica 59 (2013) 147-155.

[4] I.A. Aksay, J.A. Pask, J. Am. Ceram. Soc. 58 (1975) $507-$ 512.

[5] S.H. Risbud, J.A. Pask, J. Mater. Sci. 13 (1978) 24492454.

[6] M.V. Magliano, V.C. Pandolfelli, Cerâmica 56 (2010) 368-375.

[7] M. Panneerselvam, K.J. Rao, Chem. Mater. 15 (2003) 2247-2252.

[8] C. Sadik, E.I-E. Amrani, A. Albizane, J. Asian Ceram. Soc. 2 (2014) 310-316.

[9] A.K.P. Thakur, B. Bagchi, N.A. Hoque, S. Das, Appl. Clay Sci. 114 (2015) 349-358.

[10] J.E. Gardolinski, Química Nova 26 (2003) 30-35.

[11] R.P.S. Dutra, M.L. Varela, R.M. do Nascimento, C.A. Paskocimas, U.U. Gomes, P.T. Melo, Cerâmica Ind. 11 (2006) 42-46.

[12] F. Sahnoune, M. Chegaar, N. Saheb, P. Goeuriot, F. Valdivieso, Appl. Clay Sci. 38 (2008) 304-310.

[13] A.H. Aza, X. Turrillas, M.A. Rodriguez, T. Duran, P. Pena, J. Eur. Ceram. Soc. 34 (2014) 1409-1421.

[14] Z-Y. Deng, T. Fukasawa, M. Ando, J. Am. Ceram. Soc. 84 (2001) 485-491.

[15] Z.D. Zivkocic, Thermoch. Acta 21 (1977) 391-398.

[16] M.L. Varela, R.M. do Nascimento, A.E. Martinelli, D. Hotza, D.M.A. Melo, M.A.F. Melo, Cerâmica 51 (2005) 388-392.

[17] M.A. Sainz, F.J. Serrano, J.M. Amigo, J. Bastida, A.J. Caballero, J. Eur. Ceram. Soc. 20 (2000) 403-412.

[18] L.S. Cividanes, T.M.B. Campos, L.A. Rodrigues, D.D. Brunelli, G.P. Thim, J. Sol-Gel Sci. Technol. 55 (2010) 111125.

[19] I. Ganesh, J.M.F. Ferreira, Ceram. Int. 35 (2009) 20072015.

[20] T. Ban, K. Okada, J. Am. Ceram. Soc. 75 (1992) 227230.

(Rec. 06/10/2015, Rev. 08/01/2016, Ac. 15/03/2016) 